\title{
“O PRESIDENTE PODE MISTURAR POLÍTICA E RELIGIÃO?” O SISTEMA POLÍTICO-TEOLÓGICO DO MESSIAS A PARTIR DA SÉRIE JOÃO 8:32 ${ }^{1}$
}

\section{"Can the president mix politics with religion?" The political-theological system of the Messiah from the John 8:32 Series}

\begin{abstract}
Nelson Lellis ${ }^{2}$
Resumo:

Iniciou-se, em 2019, uma série de postagens nas redes sociais do presidente Jair Messias Bolsonaro denominada "Da série João 8:32", baseada no texto bíblico "E conhecereis a verdade e a verdade vos libertará". O objetivo era legitimar as ações, decisões e opiniões políticas a partir do verso sagrado, também adotado em sua campanha presidencial. À luz da teoria dos sistemas políticos, de David Easton, este artigo propõe desenvolver como o presidente filtra (gatekeeper) os valores religiosos e outras informações e os devolve (feedback) para a sociedade (in-put), obtendo, assim, reações que ora legitimam seus atos somando apoios, ora fazendo-o reconsiderar tais decisões ou discursos.
\end{abstract}

Palavras-chave: "Da série João: 8:32"; Bolsonaro; sistema político; religião.

\begin{abstract}
:
In 2019, a series of posts on the social networks of president Jair Messias Bolsonaro called "Da série João 8:32" began, based on the biblical text "Andy ou will know the truth and the truth will set you free". The objective was to legitimize political actions, decisions and opinions based on the sacred verse, also adopted in his presidential campaign. In the light of David Easton's theory of political systems, this article proposes to develop how the president filters (gatekeeper) religious values and other information and gives them back (feedback) to society (in-put), thus obtaining reactions that sometimes they legitimize their actions by adding support, sometimes making them reconsider such decisions or speeches.
\end{abstract}

Keywords: "Da série João 8:32"; Bolsonaro; political system; religion.

1 Submetido em: 04.05.2020. Aceito em: 13.08.2020.

"O presente trabalho foi realizado com apoio da Coordenação de Aperfeiçoamento de Pessoal de Nível Superior - Brasil (CAPES) - Código de Financiamento 001."

2 Graduação em Teologia pela Faculdade Unida de Vitória, ES. Graduando em Sociologia Faculdade Venda Nova do Imigrante, ES. Especialização em Ensino Religioso. Mestrado em Ciências das Religiões pela Faculdade Unida de Vitória, ES. Doutorando em Sociologia Política na Universidade Estadual do Norte Fluminense, RJ. Contato: nelsonlellis@gmail.com.

Protestantismo em Revista | São Leopoldo | v. 46, n. 01 | p. 19-33| Jan./jun. 2020

Disponível em: <http://periodicos.est.edu.br/index.php/nepp> 


\section{Introdução}

Em 2019, foi publicado o artigo "Evangélicos e a sociedade em rede: as eleições de 2018 e o impacto das redes sociais no Brasil" ${ }^{3}$. Nele, é analisado a presença de atores religiosos no campo das redes sociais em seu envolvimento com a política brasileira que, como destacada no título, delimitada nas eleições de 2018. Foi ainda discutida a pesquisa divulgada pelo IBGE, em que a transmissão da mensagem (em redes sociais) é a principal finalidade de acesso à internet. O objetivo, portanto, foi compreender como tais atores tiveram participação efetiva na candidatura de Jair Messias Bolsonaro à presidência do Brasil. ${ }^{4} \mathrm{O}$ resultado: os evangélicos no país oferecem forte influência, por meios variados, no Estado brasileiro. $^{5}$

Por causa desse papel histórico do cristianismo (com um crescimento constante de evangélicos), já se pode afirmar uma dimensão pública da religião, nos termos de Casanova ${ }^{6}$, ainda que num Estado laico ${ }^{7}$. Tal dimensão foi interpretada por Montero ${ }^{8}$ como uma espécie de religião "fora da igreja". E há décadas, estudos acerca da dinâmica social e da identidade cultural brasileira têm o cuidado de não isolar os dados e a importância dos movimentos produzidos na sociedade pela religião. Para J. Burity ${ }^{9}$, religião e política mostram-se inseparáveis e carecem cada vez mais de novos conceitos que ajudem aprimorar a interpretação de tão complexa ligação - o que, com este artigo, busco contribuir.

Terminadas as eleições de 2019, inaugura-se a 56a Legislatura e, com ela, uma sequência de postagens nas redes sociais do presidente onde a passagem bíblica do evangelho de João 8:32 torna-se referência. Durante o primeiro ano da referida Legislatura, foram 8

3 RODRIGUES, Nelson Lellis R. Evangélicos e a sociedade em rede. As eleições de 2018 e o impacto das redes sociais no Brasil. Revista Reflexus, v. 13, n. 21, p. 165-183, 2019.

4 Cf.: CAMURÇA, Marcelo. Religião, política e espaço público no Brasil: perspectiva histórico/sociológica e a conjuntura das eleições presidenciais de 2018. Estudos de Sociologia, Recife, v. 2, n. 25, p. 125-159, 2019. / Um poder evangélico no Estado brasileiro? mobilização eleitoral, atuação parlamentar e presença no governo Bolsonaro. v. 12, n. 25, p. 82-104, 2020.

5 Para saber mais sobre a relação de influências entre religião e política: ORO, Ari Pedro. A laicidade no Brasil e no Ocidente. Algumas considerações. Civitas, Porto Alegre, v. 11, n. 2, p. 221-237, 2011.

6 CASANOVA, José. Rethinking Secularization: a global comparative perspective. The Hedgehog Review, Charlottesville, v. 8, n. 1/2, p. 7-22, 2006. Para Casanova, há três dimensões que explicam o que é a "religião pública". São elas: a) quando a religião é um aparato do Estado; b) quando a religião atua no sistema político; c) quando a religião se transforma em força mobilizadora na sociedade civil. Neste caso, a de seria uma espécie de despir-se da fachada eclesiástica a fim de demonstrar atuação democrática na sociedade (CASANOVA, José. Public Religions in the Modern World. Chicago: The University of Chicago Press, 1994.).

7 Cf. trabalhos de: MONTERO, Paula. Controvérsias religiosas e esfera pública: repensando as religiões como discurso. Religião e Sociedade, Rio de Janeiro, 32(1), p. 167-183, 2012. / RANQUETAT JR., César Alberto. A invocação do nome de Deus nas Constituições Federais Brasileiras: Religião, Política e Laicidade. Cultura y Religión, Santiago de Chile, vol. 07, no 2, p. 86-101, 2013. / BURITY, Joanildo. A onda conservadora na política brasileira traz o fundamentalismo ao poder? In: ALMEIDA, Ronaldo; TONIOL, Rodrigo (org.). Conservadorismos, fascismos e fundamentalismos: análises conjunturais. Campinas: Editora da Unicamp, 2018. p. 15-66. / O debate conceitual sobre religiões "cívica", "civil" e "pública" proposto por Paula Montero e uma remissão para o caso do Brasil a partir de reflexões anteriores da autora. Debates do NER, v. 1, n. 33, p. 42-57, 2018.

8 MONTERO, Paula. Religião cívica, religião civil, religião pública: continuidades e descontinuidades. Debates do NER, Porto Alegre, v. 1, n. 33, p. 15-39, 2018. p. 27.

9 BURITY, Joanildo. Cultura e Identidade no campo religioso. Rio de Janeiro: UFRRJ, 1997.

Protestantismo em Revista | São Leopoldo | v. 46, n. 01 | p. 19-33| Jan./jun. 2020

Disponível em: <http://periodicos.est.edu.br/index.php/nepp> 
postagens "Da Série João 8:32" nas redes: instagram, twitter e facebook. ${ }^{10}$ A questão que por ora levanto: como o texto bíblico vai tomando forma e sendo ressignificado no discurso de Bolsonaro para, enfim, ser utilizado como um princípio legitimador de ações e opiniões políticas em sua trajetória pública?

A fim de analisar a função $D a$ Série, a primeira seção deste artigo apresenta o momento em que o texto em tela surge no discurso de Bolsonaro e como opera as ressignificações do texto ao longo de sua carreira política. Posteriormente, descrevo as 3 primeiras publicações ${ }^{11} \mathrm{Da}$ Série à luz da teoria do sistema político, em David Easton ${ }^{12}$, onde é possível abordar a vida política como um sistema de comportamento adaptativo e captar a relação entre a teologia e a política.

\section{Bolsonaro, evangélicos e João 8:32}

Não é motivo para estranhamento o fato de destacar a popularidade de Bolsonaro, que se considera católico, junto a evangélicos. Magali Cunha já observara que os evangélicos conservadores são prioridade no governo Bolsonaro ${ }^{13}$, o que não impede afirmar que determinados segmentos pentecostais e neopentecostais tiveram ampla participação em sua campanha ${ }^{14}$, bem como setores da mídia dirigidas por líderes religiosos, como a Record ${ }^{15}$. Bolsonaro mantém relação com o bispo Edir Macedo, da IURD (o que é facilmente percebido não só pelos encontros, mas também nos noticiários da Record quando o assunto é o atual governo. ${ }^{16}$

Além de ser pública a confissão de fé católica, Bolsonaro foi batizado pelo pastor Everaldo (presidente do PSC e o primeiro a candidatar-se à presidência da república [em 2014] com o título "pastor") no Rio Jordão. ${ }^{17}$ Outra relação com a igreja evangélica acontece por meio de seu terceiro casamento, com Michelle de Paula Firmo Reinaldo Bolsonaro, cuja cerimônia foi celebrada pelo pastor Silas Malafaia. Bolsonaro também costuma frequentar cultos na Igreja Batista Atitude, na Barra da Tijuca (RJ), onde sua esposa é membro.

O desdobramento do trânsito entre evangélicos pode ser percebido durante as eleições de 2018, onde a participação só deste segmento possibilitou uma diferença de mais

10 A numeração nas redes chega a contabilizar 9 postagens, porém, a contagem é interrompida na sétima e retorna na nona. Há pelo menos duas hipóteses: erro de sequência ou a postagem no 8 foi retirada e esqueceram-se de retomar a numeração.

11 Tive de optar entre as três primeiras pelo espaço que demandaria discutir uma a uma. As demais, inclusive as dos anos subsequentes, estarão presentes em outro artigo.

12 EASTON, David. An Approach to the Analysis of Political Systems. World Politics, vol. 9, n. 3, p. 383-400, 1957. p. 384.

13 Disponível em: <https://www.cartacapital.com.br/blogs/evangelicos-conservadores-sao-hoje-prioridadeno-governo-bolsonaro/?utm_source=push\&fbclid=IwAR22xB27sc6e-E4V_H-8IMxkS0ExR1_9XhEkavFitDoqiljg4NFvUH7p88>. Acesso em: 14 de out. de 2019.

14 LELLIS, Nelson; DUTRA, Roberto. "Representação religiosa na política e os conflitos de uma relação complexa: o caso da senadora Eliziane Gama”. In: LELLIS, Nelson; RIBEIRO, Cláudio de Oliveira (orgs.). Religião e Política à Brasileira: faces evangélicas no cenário político. São Paulo: Ed. Recriar, 2019. p. 37-63.

15 Disponível em: <https://theintercept.com/2020/02/23/imprensa-bolsonaro-band-sbt-record-rede-tv/>. Acesso em: 28 de fev. de 2020.

16 Disponível em: <http://www.ihu.unisinos.br/espiritualidade/78-noticias/583771-os-evangelicos-no-brasilocuparam-o-espaco-do-estado-entrevista-com-lamia-oualalou>. Acesso em: 28 de fev. de 2020.

17 Disponível em: <https://www.youtube.com/watch?v=0bEOiHNwg54>. Acesso em: 28 de fev. de 2020.

Protestantismo em Revista | São Leopoldo | v. 46, n. 01 | p. 19-33| Jan./jun. 2020

Disponível em: <http://periodicos.est.edu.br/index.php/nepp> 
de 11 milhões de votos em desfavor do candidato Fernando Haddad (PT), conforme dados da Pesquisa Datafolha, divulgados no dia 25 de outubro de $2018^{18}$ :

\section{Distribuição do eleitorado por tipo de religião}

\begin{tabular}{l|c|c|c}
\multicolumn{1}{c|}{ Religião } & Votos de Bolsonaro & Votos de Haddad & Diferença \\
\hline Católica & 29.795 .232 & 29.630 .786 & 164.446 \\
Evangélica & 21.595 .284 & 10.042 .504 & 11.552 .780 \\
Afro-brasileiras & 312.975 & 755.887 & -442.912 \\
Espíritas & 1.721 .363 & 1.457 .783 & 263.580 \\
Outra religião & 709.410 & 345.549 & 363.862 \\
\hline Total de votos & 57.796 .074 & 47.080 .987 & 10.715 .087
\end{tabular}

Antes do versículo bíblico "E conhecereis a verdade, e a verdade vos libertará" (João 8:32) fazer parte da campanha política de Bolsonaro para a presidência da república, o mesmo texto foi utilizado em outras ocasiões. Em 03 de maio de 2016, à época como deputado federal pelo PSC-RJ, discursou no plenário da Câmara dos Deputados citando a passagem bíblica e aplicando o conceito de "verdade" de maneira polissêmica:

Senhor presidente, vossa excelência como evangélico... à retaguarda tem um símbolo, uma cruz, Cristo. E à sua direita, a nossa bíblia, que é a bíblia de $90 \%$ da população brasileira. Respeitando quem não acredita, quem é ateu. E ali, em João 8:32, tá bem claro: "E conhecereis a verdade, e a verdade vos libertará". Obviamente que a verdade é Jesus, é Cristo. Trazendo para o nosso paralelo aqui, ao nosso nível dos mortais, a essa minha tribuna e tenho usado e muito. E a minha munição é a verdade e tem incomodado muita gente. [...] Eu quero agradecer neste momento a manifestação de apoio que eu tive [...] onde mais de 300 pessoas compareceram em meu condomínio apoiando as nossas verdades. A verdade nos libertará. Muito obrigado, senhor presidente, e fique com Deus. ${ }^{19}$

O verso também foi citado em entrevista ao Jornal Nacional durante sua campanha para o segundo turno das eleições. Após ter agradecido os quase 50 milhões de votos, afirmou que a motivação para sua campanha foi o texto de João 8:32:

O nosso compromisso, a nossa plataforma, a nossa bandeira, baseia-se em João 8:32 [...]. Meu muito obrigado às lideranças evangélicas, ao homem do campo, quer seja do agronegócio, quer seja da agricultura familiar, obrigado caminhoneiros, obrigado policiais civis e militares, integrantes das Forças Armadas, obrigado família brasileira, que tanto clama para que seus valores sejam respeitados e, mais ainda, que a inocência da criança em sala de aula esteja acima de tudo. Então, meu muito obrigado, em especial, à região Nordeste que, apesar de eu ter perdido lá, nunca alguém que fez oposição ao PT teve uma votação tão expressiva como eu tive. ${ }^{20}$

18 Para saber mais desta análise, ver: ALMEIDA, Ronaldo de. Bolsonaro presidente: conservadorismo, evangelismo e a crise brasileira. Novos estud. CEBRAP, v. 38, n. 1, p. 185-2013, 2019.

19 Disponível em: <https://www.facebook.com/jairmessias.bolsonaro/videos/626043744211282/>. Acesso em: 01 de jul. de 2019.

20 Disponível em: <https://www.youtube.com/watch?v=PwVgWHyWZgg>. Acesso em: 01 de jul. de 2019.

Protestantismo em Revista | São Leopoldo | v. 46, n. 01 | p. 19-33| Jan./jun. 2020

Disponível em: <http://periodicos.est.edu.br/index.php/nepp> 
O vídeo de sua propaganda eleitoral para o segundo turno foi montado com 5 minutos de duração. Os 30 primeiros segundos trouxeram a relação de Haddad, seu oponente nas urnas, com o "presidiário" Lula. Após os primeiros segundos, o narrador destaca: "Começa agora o programa do presidente livre e independente". A apresentadora destacou que "As redes sociais revolucionaram a forma como as pessoas se comunicam. E esta é uma excelente notícia que faz a nossa democracia respirar. E é das redes sociais que vêm os apoios mais importantes: o apoio do nosso povo". Neste momento, aparecem vídeos de eleitores destacando a importância da família, de ministros escolhidos pelo critério da capacidade para o cargo, da crítica à chamada "ideologia de gênero" nas escolas, exaltação a "um presidente que tem Deus no coração". Ao término, a apresentadora incentiva a campanha "via internet" a fim de levar "esperança", combater "notícias falsas" e seguir "o lema do nosso futuro presidente, se assim Deus permitir". Uma breve fala do candidato registrou que sua decisão às eleições de 2018 aconteceram em 2014. Desde lá, adotara a "bandeira João 8:32" e passa a relacionar a "verdade" neste verso como sinônimo de honestidade, uma vez que "quase ninguém acredita como regra no nosso meio político. A mentira está acima de tudo".

Para analisar o comportamento político de Bolsonaro ligado à esfera religiosa, delimitando-a na "bandeira João 8:32", mostra-se necessário compreender como o próprio uso das redes sociais tem sido considerado desde sua campanha. Castells ${ }^{21}$ observara em suas pesquisas que não se trata apenas de uma virtualidade, mas de uma construção de uma "realidade virtual". Essa constatação nos permite problematizar o deslocamento do(s) sentido(s) dos símbolos religiosos para a esfera virtual. Neste caso, os símbolos religiosos que são deslocados para o virtual como reais têm tido êxito nas transformações no âmbito da política brasileira, como demonstraram as eleições de 2018. Na leitura de Castells ${ }^{22}$, a tecnologia é utilizada para acentuar a dominação política. A mensagem (discurso) política também ganha potência transcendente.

O que proponho pensar a partir de agora é como Bolsonaro articula a "bandeira João 8:32" na rede social a partir "Da Série João 8:32"? A hipótese é que "a verdade" no verso bíblico ganha interpretações que vão além da "honestidade" e da afirmação teológica sobre Jesus; passa a ser utilizado como mecanismo legitimador para posicionamentos políticos do governo nas redes sociais, ligados a outras passagens bíblicas gerando, finalmente, uma certa "realidade virtual". João 8:32 é carregado de uma tradição religiosa no Brasil e, portanto, utilizá-lo na esfera política é a tentativa de legitimar, nos termos de Berger e Luckmann ${ }^{23}$, a produção de novos significados teológicos de caráter nômico. Vejamos como as postagens buscam trazer essa legitimação do campo simbólico pela teoria do sistema político.

\section{O sistema político-teológico do Messias}

O sistema, para Easton, é um sistema de comportamento. $\mathrm{O}$ autor propõe um modelo de abordagem teórica para o estudo da vida política. ${ }^{24}$ Segue abaixo uma interpretação do sistema para nossa ulterior interpretação:

21 CASTELLS, Manuel. A sociedade em rede. Vol. I. São Paulo: Paz e Terra, 2005. / Redes de indignação e esperança: movimentos sociais na era da internet. Rio de Janeiro: Zahar, 2013.

22 CASTELLS, 2005.

23 BERGER, Peter; LUCKMANN, Thomas. A construção social da realidade. Petrópolis: Vozes, 1985. p. 133.

24 EASTON, 1957, p. 384.

Protestantismo em Revista | São Leopoldo | v. 46, n. 01 | p. 19-33| Jan./jun. 2020

Disponível em: <http://periodicos.est.edu.br/index.php/nepp> 


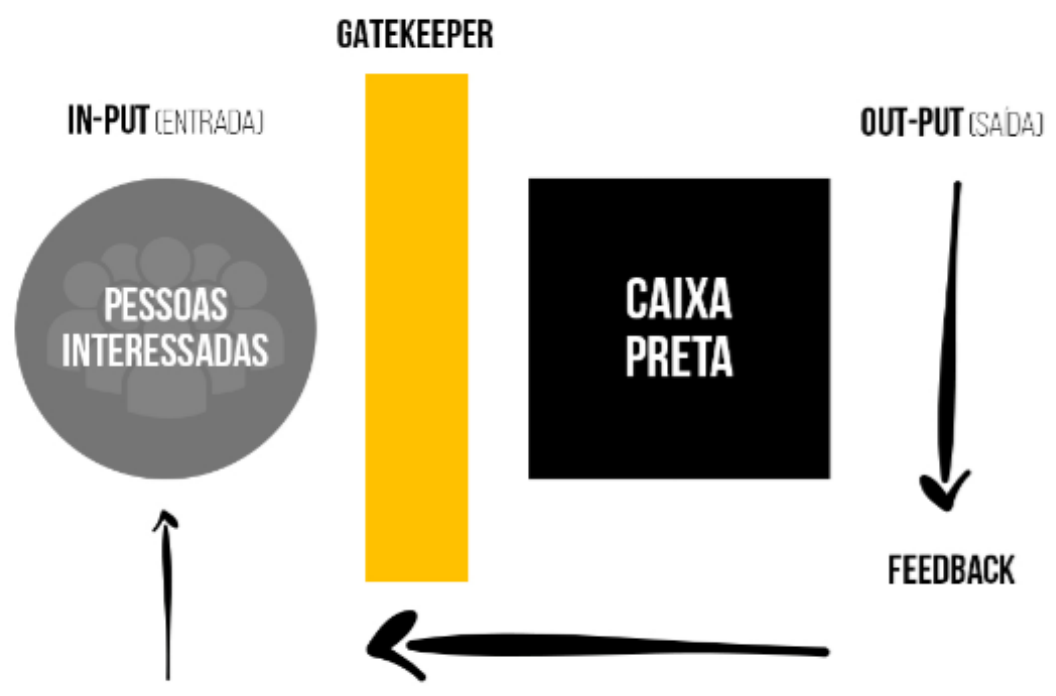

Cada categoria representa um lugar na sociedade. O in-put ("variáveis sumárias" 25) é o lugar da demanda, dos grupos sociais, dos códigos religiosos. O gatekeeper é uma espécie de filtragem dessas demandas para serem enviadas para a caixa preta (sistema político: para onde são convertidas as demandas; onde são decididas politicamente como serão, se serão, em que medida serão assistidas as solicitações), e, posteriormente, reenviadas (feedback) à sociedade. Quem realiza esse trabalho são instituições (gatekeeper) que selecionam, racionalizam, categorizam as demandas, tais como: sindicatos, partidos políticos, igrejas, associações de bairro. Após a sistematização das demandas, são endereçadas ao sistema. Essa dinâmica mostra-se cíclica, onde há influência de ambos os lados, todavia, ao ser discutida e desenvolvida na esfera da caixa preta, a devolução de determinada demanda ou código reaparece com outros valores e intenções.

No cenário onde o segmento evangélico e o presidente, tal como já destacamos, demonstra um elo significativo, assim interpretamos através do sistema:

- In-put: a ala conservadora evangélica pode ser encontrada neste ambiente; junto dela, seus códigos, suas demandas, seus valores morais.

- Gatekeeper: nossa hipótese é que Bolsonaro tenha uma rede que o auxilia na filtragem de tais categorias no intuito de fazer delas uma bandeira e um ethos de ligação com a população evangélica.

- Caixa Preta: ambiente das decisões, de como utilizar, publicar, discursar, tendo como objetivo responder às demandas de parte do segmento evangélico capaz, inclusive, de reforçar a identidade religiosa e o apoio político.

25 EASTON, David. Uma teoria de análise política. Rio de Janeiro: Zahar Ed., 1968. p. 155.

Protestantismo em Revista | São Leopoldo | v. 46, n. 01 | p. 19-33| Jan./jun. 2020

Disponível em: <http://periodicos.est.edu.br/index.php/nepp> 
- Feedback: de que maneira, no caso específico deste artigo, as publicações Da Série João 8:32 impactam não só seus seguidores, mas também, outros setores da sociedade brasileira?

\section{Da Série João 8:32 (1): “Existe fome no Brasil?”}

A primeira postagem "Da Série João 8:32" ocorreu no dia 5 de agosto de 2019. 0 título traz uma pergunta em caixa alta: "EXISTE FOME NO BRASIL?". A foto com Ministro da Cidadania Osmar Terra, que tem Bolsonaro vestido com a faixa presidencial, foi tirada na cerimônia de nomeação dos ministros e acompanha o seguinte texto:

\footnotetext{
"Somados o Bolsa Família, o Benefício de Prestação Continuada (BPC) e a aposentadoria rural, há uma massa de $\mathrm{R} \$ 200$ bilhões que vão para o bolso dos mais pobres todos os anos. Logo, se você entender a fome como sistêmica e endêmica, o Brasil não a tem". Ministro da Cidadania, Osmar Terra.

Presidente Jair Bolsonaro. (Grifo meu)
}

O breve texto é citação de uma fala do ministro Osmar Terra. Bolsonaro encerra a postagem com seu nome, como que chancelando a citação. No dia 19 de julho, Bolsonaro comentou pela primeira vez sobre o tema da fome no país - uma demanda social (in-put). Foi durante um encontro com jornalistas estrangeiros, onde declarou: "falar que se passa fome no Brasil é uma grande mentira" ${ }^{26}$. Como o sistema é cíclico, após o feedback, houve uma outra reação de grupos diversos na sociedade. Após críticas, recuou: "alguns [brasileiros] passam fome"27.

O que Bolsonaro quer dizer quando usa a palavra "fome"? O conceito de fome endêmica, utilizado na postagem, foi introduzido por José de Castro, em seu livro Geografia da Fome (primeira publicação em 1946). ${ }^{28}$ Castro foi um ativista contra a fome no país e morreu em 1974. No livro, buscou apresentar um mapa da fome e estabelece ali uma série de nomenclaturas capazes de orientar estudos sobre o tema. Em 2008, na revista Cadernos de Saúde Pública, o cientista Francisco de Assis Guedes de Vasconcelos publicou um artigo sobre a obra de Castro, onde enfatiza o que pode ser chamado de área de fome endêmica: trata-se de "uma determinada área geográfica em que pelo menos metade da população apresenta nítidas manifestações de carências nutricionais permanentes"29.

Para se utilizar tal conceito, seria necessário afirmar, numa plataforma macro, que o país possui mais de 100 milhões de pessoas privadas de acesso adequado a alimentos. Se utilizado em plataforma micro, como para "determinada religião no país", tem-se complicações na interpretação porque os saldos negativos são crescentes.

26 Disponível em: <https:/g1.globo.com/politica/noticia/2019/07/19/falar-que-se-passa-fome-no-brasil-euma-grande-mentira-diz-bolsonaro.ghtml>. Acesso em: 28 de fev. de 2020.

27 Disponível em: <https://www1.folha.uol.com.br/poder/2019/07/apesar-de-menor-fome-ainda-afeta-obrasil-aponta-orgao-da-onu.shtml>. Acesso em: 28 de fev. de 2020.

28 CASTRO, Josué. Geografia da fome: o dilema brasileiro: pão ou aço. 10a ed. Rio de Janeiro: Edições Antares, 1984.

29 VASCONCELOS, Francisco de Assis Guedes de. Josué de Castro e a Geografia da Fome no Brasil. Cad. Saúde Pública, v. 24, n. 11, p. 27-10-2717, 2008. p. 2.711.

Protestantismo em Revista | São Leopoldo | v. 46, n. 01 | p. 19-33| Jan./jun. 2020

Disponível em: <http://periodicos.est.edu.br/index.php/nepp> 
Tendo por base o relatório d'O estado de segurança alimentar e da nutrição no mundo, divulgado pela Organização das Nações Unidas para Alimentação e Agricultura (FAO), os números apresentam uma queda da desnutrição: entre os anos de 2004-2006 eram 4,6\%; entre os anos de 2016-2018 caiu para menos de 2,5\%. Entre os anos de 2004-2006, cerca de 8,6 milhões de pessoas estavam em situação de fome. Levando em consideração que desnutridos estão na casa dos 5 milhões, houve uma queda de $42 \%{ }^{30} \mathrm{Em}$ relação aos famintos, houve uma diminuição no período compreendido entre 2004 e 2014 (ano em que o Brasil saiu do mapa da fome). Foram 26,5 milhões de pessoas que deixaram a pobreza.

A questão é que, segundo os dados, a fome continua existindo no país e segundo o último levantamento da FAO, mais de 5 milhões de brasileiros ainda estão em situação crítica. Um relatório da ONU, divulgado em novembro de 2018, no Panorama da Segurança Alimentar e Nutricional na América Latina e Caribe, indicou que nos últimos anos o número de famintos tem aumentado ligeiramente. Entre os anos de 2015-2017, desnutridos era de 5,2 milhões. 0 total calculado entre os períodos de 2014-2016 e 2013-2015 foi de 5,1 milhões. Em 2010, 4,9 milhões. ${ }^{31}$

O conceito utilizado pelo ministro e assinado pelo presidente parece querer remodelar as falas anteriores deste levando em consideração a plataforma macro, onde seria impossível dizer que mais de 100 milhões de brasileiros não têm acesso à alimentação adequada.

Em entrevista ao Estadão antes da postagem serial, José Graziano, engenheiro agrônomo e ex-diretor-geral da FAO, disse: "não se combate a fome dizendo que ela não existe" ${ }^{\prime 2}$. Contudo, percebendo que o discurso do atual presidente é carregado de intenções voltadas às maiorias - ou seja, uma plataforma macro e, por isso, confirmar a frase do seu ministro negando a fome endêmica no Brasil - confirma, igualmente, sua visão religiosa acerca de uma espécie de Cristo das maiorias, como já preconizava em um de seus discursos antes de vencer as eleições (ver próxima seção). E isso nos abre as portas para a próxima postagem.

\section{Da Série João 8:32 (2): “O presidente pode misturar política com religião?”}

A segunda postagem, interpreto como o desdobramento de seu discurso/comício ocorrido em fevereiro de 2017, onde afirmara:

Como somos um país cristão, Deus acima de tudo! Não existe essa historinha de Estado laico, não. É Estado cristão! [grito de um eleitor: "É Jesus Cristo!"] E quem for contra, que se mude! Vamos fazer o Brasil para as maiorias. As minorias têm que se curvar às maiorias. As leis devem existir para defender as maiorias. As minorias se adéquam ou simplesmente desaparecem. ${ }^{33}$ (Grifos meus)

30 Disponível em: <http://www.fao.org/americas/noticias/ver/pt/c/1152189/>. Acesso em: 15 de jan. de 2020.

31 Disponível em: <http://www.fao.org/americas/prioridades/seguridad-alimentaria/pt/>. Acesso em: $15 \mathrm{de}$ jan. de 2020.

32 Disponível em: <https://exame.abril.com.br/brasil/nao-se-combate-a-fome-dizendo-que-ela-nao-existe-dizex-diretor-da-onu/>. Acesso em: 15 de jan. de 2020.

33 Disponível em: <https://paraibaonline.com.br/2017/02/bolsonaro-discursa-em-campina-a-minoria-temque-se-curvar-para-a-maioria/>. Acesso em 29 de fev. de 2020.

Protestantismo em Revista | São Leopoldo | v. 46, n. 01 | p. 19-33| Jan./jun. 2020

Disponível em: <http://periodicos.est.edu.br/index.php/nepp> 
O título da segunda postagem "Da Série João 8:32", feita no dia 06 de agosto de 2019, traz a seguinte pergunta: "O PRESIDENTE PODE MISTURAR POLÍTICA COM RELIGIÃO?". E responde reavaliando sua anterior afirmação sobre o Estado laico, mas potencializando a ideia de "maioria" ligada agora ao texto de Romanos: "O Estado é laico, SIM. Mas o presidente da República é CRISTÃO, como aproximadamente $90 \%$ do povo brasileiro também o É. Romanos 8:31, se Deus é por nós quem será contra nós?". ${ }^{34}$

Bolsonaro destaca em caixa alta o fato do Estado ser laico, mas o contrapõe, ao mesmo tempo posicionando a pessoa (dele) como cristã ligada ao cargo ("presidente da República") e afirmando à maioria da população brasileira no mesmo segmento religioso, ainda que não tenha feito distinção de outras denominações que professam a fé em Jesus. Na leitura a partir do sistema que aqui propomos, sua leitura do in-put pretende observar, politicamente, as estatísticas sobre cristãos no país. Filtrar tal informação para a caixa preta o daria melhores condições para acessar grande parte deste segmento religioso com sucesso.

A pesquisa "Retratos da Sociedade Brasileira - perspectivas para as eleições de 2018 "35, realizada pelo Instituto Brasileiro de Opinião Pública e Estatística (IBOPE) ${ }^{36}$, divulgou que $79 \%$ dos brasileiros concordam total ou parcialmente que é importante que o candidato à presidência da república acredite em Deus. $29 \%$ declararam que é muito importante que o candidato seja da mesma denominação religiosa que elas. Esse gatekeeper parece ter sido essencial na campanha do Messias.

A pergunta "quem é contra nós?" denota os espaços de conflito entre maioria (o nós) e a minoria (eles) na esfera do in-put. "Eles" não podem ser contra o "nós" por causa de Jesus. Por dedução: logo, o Jesus das maiorias, dos $90 \%$. Desta forma, o que interessaria na caixa preta seria cuidar dos interesses de um grupo seleto e que compõe a maioria dentre os brasileiros. Essa relação entre o "nós" e o "eles" é bem discutida teoricamente por Laclau ${ }^{37}$ e Moufee ${ }^{38}$ no que se refere ao tema do populismo, em que a ideia na esfera política não baseiase no diálogo com o outro, mas na eliminação.

A imagem postada juntamente com o texto apresenta Bolsonaro vestido de um terno preto, com gravata azul listrada de branco e uma camisa branca. Um semblante leve à frente de vitrais coloridos e desfocados ao fundo. A foto o enquadra de baixo para cima, de modo que aquele que acessa a postagem tem a sensação de estar abaixo do presidente, mas vendoo de forma definida. Os vitrais, aparentemente religiosos, embaçados. O que sugere uma interpretação do próprio cenário: a relação com os segmentos religiosos de maneira "embaçada", "não definida"; uma bricolagem religiosa que vai do neopentecostalismo brasileiro à relação com o judaísmo a partir do contato com o primeiro ministro de Israel,

34 Em 2019, durante a 27ạ Marcha Para Jesus, Jair Bolsonaro repetiu a frase: “Estado é laico, mas ele é cristão". Disponível em: <https://exame.abril.com.br/brasil/o-estado-e-laico-mas-ele-e-cristao-diz-bolsonaro-namarcha-para-jesus/>. Acesso em: 29 de fev. de 2020.

35 Disponível em: <https://www.portaldaindustria.com.br/estatisticas/rsb-43-perspectivas-para-eleicoes-de2018/>. Acesso em: 20 de jan. de 2020.

36 A pesquisa foi encomendada pela Confederação Nacional da Indústria (CNI). O IBOPE entrevistou 2 mil pessoas de 127 municípios entre os dias 7 e 10 de dezembro de 2017. Disponível em: <https://www.portaldaindustria.com.br/estatisticas/rsb-43-perspectivas-para-eleicoes-de-2018/>. Acesso em: 10 de abr. de 2020.

37 LACLAU, Ernesto. A razão populista. São Paulo: Três Estrelas, 2013.

38 MOUFEE, Chantal. Por um populismo de esquerda. São Paulo: Autonomia Literária, 2019.

Protestantismo em Revista | São Leopoldo | v. 46, n. 01 | p. 19-33| Jan./jun. 2020

Disponível em: <http://periodicos.est.edu.br/index.php/nepp> 
Benjamin Netanyahu39 - o mesmo que disse em 28 de dezembro de 2018 que "Israel é a terra prometida e Brasil é a terra da promessa"; e, dirigindo-se a Bolsonaro, afirmou: "E o senhor encabeça a boa gestão desse país para concretizar essa promessa" ${ }^{40}$.

A partir do sistema aqui aplicado, é possível observar que a segunda postagem demonstra que apenas a religião cristã é citada em seu discurso; as demais, como "outras religiões". E a questão retórica que surge: O presidente pode falar de religião? Provavelmente, o "falar de religião" na caixa preta não interferisse politicamente na sociedade, com tantas outras demandas e códigos, se esse ponto de referência religioso considerasse, em conjuntura, todas as manifestações de crença. O executivo "falar de religião" não é o mesmo que discursar e programar suas ações a partir da religião.

\section{Da Série João 8:32 (3): Nada há encoberto que não haja de ser descoberto}

No dia 10 de agosto, a terceira postagem da série foi lançada sem título. A imagem é o perfil de Bolsonaro em um púlpito semelhante a de uma igreja. Na postagem, há uma citação de um "autor desconhecido" seguida de outro texto bíblico:

\footnotetext{
"Mais do que nunca é necessário reunir Forças. Há muito mais brasileiros com inclinações de caráter sadio, que mentes algemadas pela ilusão das vantagens pessoais e do poder". (Autor desconhecido). - Lucas 12:2: "Mas nada há encoberto que não haja de ser descoberto; nem oculto, que não haja de ser sabido". (Grifos meus).
}

A frase é colocada como autoria desconhecida, mas facilmente é encontrada na internet. Trata-se de uma mensagem de Bezerra de Menezes (político, "médico dos pobres", que viveu no séc. XIX, no Rio de Janeiro), que teria sido psicografada pelo médium Wanderley de Oliveira. Foi escrita no dia 27 de julho, ou seja, 14 dias antes desta postagem Da Série. Muito curiosamente, o site do médium traz uma mensagem dirigida à nação brasileira. Nela, também está a passagem bíblica de Lucas 12,2. Transcrevi os principais trechos:

\footnotetext{
O Brasil, como um corpo adoecido, recebe esse "bisturi da verdade", extirpando o câncer maligno que quase o levou à morte.

Será necessária muita coragem no coração para refletir essa autenticidade. A guerra não é de ideologias partidárias, e sim da verdade contra a mentira.

Desde o individual ao coletivo, penetramos no lema profetizado por Jesus: "Mas nada há encoberto que não haja de ser descoberto, nem oculto que não haja de ser sabido" (Lucas 12.2)

O brasileiro cansado da inconsequência administrativa precisa ser educado para entender que a bondade divina não o desamparou e lhe prepara um banquete de novas oportunidades.
}

39 Disponível em: <https://g1.globo.com/mundo/noticia/2019/04/01/bolsonaro-visita-muro-das-lamentacoesao-lado-de-netanyahu.ghtml>. Acesso em: 29 de fev. de 2020.

40 Disponível em: <https://www1.folha.uol.com.br/mundo/2018/12/israel-e-a-terra-prometida-e-o-brasil-e-aterra-da-promessa-diz-netanyahu-em-encontro-com-bolsonaro.shtml>. Acesso em: 29 de fev. de 2020.

Protestantismo em Revista | São Leopoldo | v. 46, n. 01 | p. 19-33| Jan./jun. 2020

Disponível em: <http://periodicos.est.edu.br/index.php/nepp> 
[...] é fundamental para fortificar esses tenros embriões da vitalidade dos novos pilares da política brasileira, assentada em honestidade, nobreza moral e amor à pátria. ${ }^{41}$ (Grifos meus)

Considerando as expressões destacadas acima, não se pode descartar a probabilidade de um apoio ao governo, uma vez que espíritas também assumiram publicamente seu voto (foram 1.721.363 votos) a Bolsonaro. Além disso, um dos pilares que a "Casa Planetária" tinha como missão espiritual para o Brasil era a "fertilização de valores conservadores. Um país com uma identidade patriótica, longe da corrupção dos costumes". E, por fim, alerta: "mais do que nunca é necessário reunir forças. Há muito mais brasileiros com inclinações de caráter sadio do que mentes algemadas pela ilusão das vantagens pessoais e do poder" (grifo meu).

A última frase pode ser uma referência a Deltan Dallagnol e sua atividade na Procuradoria Geral da República. No perfil "Bolsonaro Opressor 2.0", gerenciado pelo assessor de gabinete do presidente, Tércio Arnaud Tomaz, diz: "O cara [Deltan] é esquerdista estilo PSOL". Esta afirmação esteve baseada em fotos e mensagens que Deltan compartilhou demonstrando ser favorável a investigações contra o governo, contra a ditadura e críticas à proposta de armamento. Bolsonaro elenca alguns temas que devem ser observados para o indicado à PGR:

Algumas perguntas, ou pesquisa, a serem feitas ao indicado para a PGR, no tocante aos seguintes assuntos: 1- Desarmamento; 2- Ideologia de gênero; 3- Direitos humanos; 4- Amazônia; 5- Excludente de ilicitude; 6- Comissão da Verdade; 7Reserva indígena; 8- ONGs na Amazônia; 9- Forças Armadas e Auxiliares; 10- Meioambiente; outras...

Segundo a postagem, um procurador da república deve ter bem abertas suas opiniões acerca dos temas acima. Relembrando a citação do médium: "[...] mentes algemadas pela ilusão das vantagens pessoais e do poder". Com isso, Bolsonaro focaria criticamente nas vantagens pessoais e de poder de Dallagnol, objetivando suas próprias pautas ligadas a seu governo; procurando contemplar, sobretudo, o lado de uma moralidade igualmente pregada pela religião (gatekeeper). O que está oculto, será revelado. A dúvida seria o motivo porque Bolsonaro ocultou a fonte registrada por um médium, colocando "Autor Desconhecido", para legitimar seus argumentos. Talvez o espiritismo fosse uma barreira para os seus maiores apoiadores: os evangélicos conservadores. Por isso, em seu feedback não poderia desconsiderar tal público.

\section{Considerações finais}

Pela teoria dos sistemas, podemos afirmar, diante das postagens aqui analisadas, que caixa preta do governo adota uma gramática teológico-religiosa do segmento evangélico, onde possui uma ligação simbólica e de códigos linguísticos e de onde vêm seus maiores apoiadores. Também foi possível perceber que a reação de outros grupos, após o feedback

41 Disponível em: <https://www.cultseraridades.com.br/mensagem-de-bezerra-de-menezes-a-nacaobrasileira/>. Acesso em: 14 de out. de 2019.

Protestantismo em Revista | São Leopoldo | v. 46, n. 01 | p. 19-33| Jan./jun. 2020

Disponível em: <http://periodicos.est.edu.br/index.php/nepp> 
discursivo do presidente (sobre a fome, por exemplo), fez com que o mesmo revisse os termos utilizados, uma vez que o sistema é cíclico.

Com feedbacks semelhantes, Bolsonaro, ao longo de sua trajetória política, tem recebido críticas (de grupos situados no in-put) resultando em reconsiderações do executivo. Só nos primeiros nove dias de governo, o presidente "voltou atrás" nove vezes. ${ }^{42}$ Também se retratou acerca de imigrantes brasileiros nos EUA, ${ }^{43}$ "voltou atrás" pedindo revogação de medida que excluiria atividades de $\mathrm{MEI}^{44}$, dentre outras.

Em pesquisa feita pelo Instituto Paraná em abril de 2020 (com 2.006 eleitores de 182 municípios de todos os estados do país), $60 \%$ dos brasileiros consideram o governo do Messias pior do que se esperava, contudo, em possível cenário eleitoral para 2022, Bolsonaro aparece em primeiro lugar com $27 \%$ das intenções de voto, enquanto Sérgio Moro, com $18,1 \%$. Tais números sugerem a seguinte interpretação: ainda que haja um número descontente com o governo e que Bolsonaro redefina determinadas ações e discursos após reação de grupos situados no in-put, parece não haver ruptura considerável de setores religiosos, sobretudo, evangélicos. Neste caso, possivelmente, a ressignificação do que é a "verdade" no evangelho de João esteja buscando outro tipo de comprometimento, o que poderá, inclusive, ajudar a construir um novo conceito teológico de "verdade" para legitimação de determinados atos e discursos na relação entre religião e política. Tudo isso contribui para a "confessionalização da política" 45 e a "publicização da religião"46.

Outro dado: o jogo de Bolsonaro em relação às "verdades" manipuladas através das mídias (conhecido como "gabinete do ódio"). As "bolhas de interesse" criadas pelos algoritmos e a cultura numérica fazem desaparecer a curiosidade de verificação por parte dos eleitores. As redes sociais, sem dúvida, surgem como elemento importante nesse jogo político-teológico de construção de "verdades", onde grande parte da população não investe tempo em refletir sobre o conteúdo escrito ou falado. Possivelmente, o feedback que levaria o governo reconsiderar essa criação de "verdades" seria a partir de uma migração da "linguagem empobrecida"47, causada pelo neoliberalismo (e que cria pensamentos estereotipados como "bandido bom é bandido morto", "vai para Cuba"), para uma linguagem não-simplificada, em que as informações não são acolhidas por serem apenas "convicções" de seus destinatários - tornando-as atrativas para serem consumidas -, e sim, pela filtragem crítica que, além de enriquecer, complexifica a exposição (das informações) através de dados e as devolve amadurecidas para um novo debate.

\section{Referências}

42 Disponível em: <https://www.jornalopcao.com.br/ultimas-noticias/bolsonaro-volta-atras-nove-vezes-emnove-dias-como-presidente-157761/>. Acesso em: 01 de fev. de 2020.

43 Disponível

<https://www.em.com.br/app/noticia/politica/2019/03/19/interna politica,1039290/bolsonaro-voltaatras-e-diz-que-errou-em-declaracao-contra-imigrantes.shtml >. Acesso em: 01 de fev. de 2020.

44 Disponível em: <https://economia.ig.com.br/2019-12-08/bolsonaro-volta-atras-e-pede-revogacao-demedida-que-excluiu-atividades-de-mei.html>. Acesso em: 01 de fev. de 2020.

45 PIERUCCI, Antonio Flávio. Representantes de Deus em Brasília: a bancada evangélica na Constituinte. Ciências Sociais Hoje, n. 11, p. 104-132, 1989.

46 CASANOVA, 2006.

47 CASARA, Rubens. Bolsonaro: o mito e o sintoma. São Paulo: Editora Contracorrente, 2020.

Protestantismo em Revista | São Leopoldo | v. 46, n. 01 | p. 19-33| Jan./jun. 2020

Disponível em: <http://periodicos.est.edu.br/index.php/nepp> 
ALMEIDA, Ronaldo de. Bolsonaro presidente: conservadorismo, evangelismo e a crise brasileira. Novos estud. CEBRAP, v. 38, n. 1, p. 185-2013, 2019.

BERGER, Peter; LUCKMANN, Thomas. A construção social da realidade. Petrópolis: Vozes, 1985.

BURITY, Joanildo. A onda conservadora na política brasileira traz o fundamentalismo ao poder? In: ALMEIDA, Ronaldo; TONIOL, Rodrigo (Org.). Conservadorismos, fascismos e fundamentalismos: análises conjunturais. Campinas: Editora da Unicamp, 2018. p. 15-66. / O debate conceitual sobre religiões "cívica", "civil" e "pública" proposto por Paula Montero e uma remissão para o caso do Brasil a partir de reflexões anteriores da autora. Debates do NER, v. 1, n. 33, p. 42-57, 2018.

. Cultura e Identidade no campo religioso. Rio de Janeiro: UFRRJ, 1997.

CAMURÇA, Marcelo. Religião, política e espaço público no Brasil: perspectiva histórico/sociológica e a conjuntura das eleições presidenciais de 2018. Estudos de Sociologia, Recife, v. 2, n. 25, p. 125-159, 2019.

. Um poder evangélico no Estado brasileiro? mobilização eleitoral, atuação parlamentar e presença no governo Bolsonaro. v. 12, n. 25, p. 82-104, 2020.

CASANOVA, José. Public Religions in the Modern World. Chicago: The University of Chicago Press, 1994.

Rethinking Secularization: a global comparative perspective. The Hedgehog Review, Charlottesville, v. 8, n. 1/2, p. 7-22, 2006.

CASARA, Rubens. Bolsonaro: o mito e o sintoma. São Paulo: Editora Contracorrente, 2020.

CASTELLS, Manuel. A sociedade em rede. Vol. I. São Paulo: Paz e Terra, 2005.

. Redes de indignação e esperança: movimentos sociais na era da internet. Rio de Janeiro: Zahar, 2013.

CASTRO, Josué. Geografia da fome: o dilema brasileiro: pão ou aço. 10a ed. Rio de Janeiro: Edições Antares, 1984.

EASTON, David. An Approach to the Analysis of Political Systems. World Politics, vol. 9, n. 3, p. 383-400, 1957.

. Uma teoria de análise política. Rio de Janeiro: Zahar Ed., 1968.

LACLAU, Ernesto. A razão populista. São Paulo: Três Estrelas, 2013.

LELLIS, Nelson; DUTRA, Roberto. "Representação religiosa na política e os conflitos de uma relação complexa: o caso da senadora Eliziane Gama”. In: LELLIS, Nelson; RIBEIRO, Cláudio de Oliveira (Org.). Religião e Política à Brasileira: faces evangélicas no cenário político. São Paulo: Ed. Recriar, 2019. p. 37-63.

MONTERO, Paula. Controvérsias religiosas e esfera pública: repensando as religiões como discurso. Religião e Sociedade, Rio de Janeiro, 32(1), p. 167-183, 2012.

. Religião cívica, religião civil, religião pública: continuidades e descontinuidades.

Debates do NER, Porto Alegre, v. 1, n. 33, p. 15-39, 2018. p. 27.

MOUFEE, Chantal. Por um populismo de esquerda. São Paulo: Autonomia Literária, 2019. 
ORO, Ari Pedro. A laicidade no Brasil e no Ocidente. Algumas considerações. Civitas, Porto Alegre, v. 11, n. 2, p. 221-237, 2011.

PIERUCCI, Antonio Flávio. Representantes de Deus em Brasília: a bancada evangélica na Constituinte. Ciências Sociais Hoje, n. 11, p. 104-132, 1989.

RANQUETAT JR., César Alberto. A invocação do nome de Deus nas Constituições Federais Brasileiras: Religião, Política e Laicidade. Cultura y Religión, Santiago de Chile, vol. 07, no 2, p. 86-101, 2013.

RODRIGUES, Nelson Lellis R. Evangélicos e a sociedade em rede. As eleições de 2018 e o impacto das redes sociais no Brasil. Revista Reflexus, v. 13, n. 21, p. 165-183, 2019.

VASCONCELOS, Francisco de Assis Guedes de. Josué de Castro e a Geografia da Fome no Brasil. Cad. Saúde Pública, v. 24, n. 11, p. 27-10-2717, 2008.

\section{Sítios eletrônicos}

$<$ https://exame.abril.com.br/brasil/nao-se-combate-a-fome-dizendo-que-ela-nao-existe-dizex-diretor-da-onu/>. Acesso em: 15 de jan. de 2020.

$<$ https://exame.abril.com.br/brasil/o-estado-e-laico-mas-ele-e-cristao-diz-bolsonaro-namarcha-para-jesus/>. Acesso em: 29 de fev. de 2020.

<https://g1.globo.com/mundo/noticia/2019/04/01/bolsonaro-visita-muro-das-lamentacoesao-lado-de-netanyahu.ghtml>. Acesso em: 29 de fev. de 2020.

<https://g1.globo.com/politica/noticia/2019/07/19/falar-que-se-passa-fome-no-brasil-euma-grande-mentira-diz-bolsonaro.ghtml>. Acesso em: 28 de fev. de 2020.

$<$ https://paraibaonline.com.br/2017/02/bolsonaro-discursa-em-campina-a-minoria-temque-se-curvar-para-a-maioria/>. Acesso em 29 de fev. de 2020.

<https://theintercept.com/2020/02/23/imprensa-bolsonaro-band-sbt-record-rede-tv/>. Acesso em: 28 de fev. de 2020.

$<$ https://www.cartacapital.com.br/blogs/evangelicos-conservadores-sao-hoje-prioridadeno-governo-bolsonaro/?utm_source=push\&fbclid=IwAR22xB27sc6e-E4V_H-

8IMxkS0ExR1_9XhEkavFitDo-qiljg4NFvUH7p88>. Acesso em: 14 de out. de 2019.

<https://www.cultseraridades.com.br/mensagem-de-bezerra-de-menezes-a-nacaobrasileira/>. Acesso em: 14 de out. de 2019.

<https://www.em.com.br/app/noticia/politica/2019/03/19/interna_politica,1039290/bolso naro-volta-atras-e-diz-que-errou-em-declaracao-contra-imigrantes.shtml>. Acesso em: $01 \mathrm{de}$ fev. de 2020.

<https://www.facebook.com/jairmessias.bolsonaro/videos/626043744211282/>. Acesso em: 01 de jul. de 2019.

<http://www.fao.org/americas/noticias/ver/pt/c/1152189/>. Acesso em: 15 de jan. de 2020. <http://www.fao.org/americas/prioridades/seguridad-alimentaria/pt/>. Acesso em: 15 de jan. de 2020.

Protestantismo em Revista | São Leopoldo | v. 46, n. 01 | p. 19-33| Jan./jun. 2020

Disponível em: <http://periodicos.est.edu.br/index.php/nepp> 
<https://www.jornalopcao.com.br/ultimas-noticias/bolsonaro-volta-atras-nove-vezes-emnove-dias-como-presidente-157761/>. Acesso em: 01 de fev. de 2020.

$<$ https://www.portaldaindustria.com.br/estatisticas/rsb-43-perspectivas-para-eleicoes-de2018/>. Acesso em: 10 de abr. de 2020.

$<$ http://www.ihu.unisinos.br/espiritualidade/78-noticias/583771-os-evangelicos-no-brasilocuparam-o-espaco-do-estado-entrevista-com-lamia-oualalou>. Acesso em: $28 \mathrm{de}$ fev. de 2020.

<https://www.youtube.com/watch?v=PwVgWHyWZgg>. Acesso em: 01 de jul. de 2019. <https://www.youtube.com/watch?v=0bEOiHNwg54>. Acesso em: $28 \mathrm{de} \mathrm{fev.} \mathrm{de} 2020$. $<$ https://www1.folha.uol.com.br/poder/2019/07/apesar-de-menor-fome-ainda-afeta-obrasil-aponta-orgao-da-onu.shtml>. Acesso em: 28 de fev. de 2020.

$<$ https://www1.folha.uol.com.br/mundo/2018/12/israel-e-a-terra-prometida-e-o-brasil-e-aterra-da-promessa-diz-netanyahu-em-encontro-com-bolsonaro.shtml>. Acesso em: 29 de fev. de 2020. 